\title{
El hilo de la historia: del patrimonio mueble al intangible. Rescatando el patrimonio textil sedero
}

\section{Ester Alba ${ }^{a}$, Mar Gaitána ${ }^{a}$ Arabella León ${ }^{b}$ y Jorge Sebastián ${ }^{a}$}

${ }^{a}$ Universitat de València. Departamento de Historia del Arte. Av. de Blasco Ibáñez, 28, 46010 València, Spain; esther.alba@uv.es (E.A.); silknow@uv.es (M.G); jorge.sebastian@uv.es, bGarin 1820 S.A. Calle Ramón de Villarroya 1, Moncada, 46113, Spain; aleon@garin1820.com

\begin{abstract}
Resumen
El patrimonio de la seda constituye un tipo de patrimonio integral, es decir, en el que se pueden encontrar elementos tangibles e intangibles además de ser un patrimonio vivo fuertemente conectado con su comunidad. Es además un caso paradigmático, ya que tiene asociados elementos inmateriales que van desde literatura, a la recogida de la morera, o las técnicas tradicionales de tejido. Además, el desarrollo de su actividad ha dejado una impronta en diversas ciudades con monumentos e incluso marca el urbanismo de las mismas. Es un patrimonio vivo presente en diversas comunidades y constituye un elemento de creatividad presente en los diseños más contemporáneos de la moda actual.

En este artículo se abordan los principales resultados del proyecto SILKNOW, financiado por la Unión Europea en el marco de Horizonte 2020 y se da valor a este patrimonio proponiendo la elaboración de un plan nacional que garantizará la salvaguarda de técnicas y saberes ligados a las técnicas de tejido, a través de la memoria oral y los procesos de conservación, documentación y registro. Buscando la comprensión de esas técnicas a través de la tecnología para hacer ese conocimiento accesible, al tiempo que se potencia el conocimiento de la seda.
\end{abstract}

Palabras clave: patrimonio inmaterial, seda, tecnología, plan nacional, documentación.

\begin{abstract}
Silk heritage belongs to the so-called integral heritage type, which means that tangible and intangible elements can be found in one piece. Moreover, silk is a living heritage strongly connected with its community. It is paradigmatic case, where its intangible elements go from literature, to mulberry farming, or traditional weaving techniques. Also, activities surrounding silk trade have left an imprint on various cities in monuments and even marking their town planning. Nowadays, silk is a living heritage in various communities and constitutes an element of creativity that can be appreciated in the current fashion trends.
\end{abstract}

This paper addresses the main results of the SILKNOW project, funded by the European Union within the framework of Horizon 2020, and will give value to this heritage by proposing the elaboration of a national plan that will guarantee the safeguarding of techniques and knowledge linked to weaving techniques, through oral memory and conservation, documentation and cataloging. Within this project, we seek to understand these techniques through technology in order to make this knowledge accessible, while promoting silk knowledge among society.

Keywords: intangible heritage, silk, technology, national plan, documentation. 


\section{Introducción}

El patrimonio de la seda constituye un tipo de patrimonio integral, es decir, en el que se pueden encontrar elementos tangibles como la fileta (Fig. 1), e intangibles además de ser un patrimonio vivo fuertemente conectado con su comunidad. Es además un caso paradigmático, ya que tiene asociados elementos inmateriales que van desde literatura, a la recogida de la morera, o las técnicas tradicionales de tejido. Pero la sedería va más allá, puesto que el desarrollo de su actividad ha dejado una impronta significativa en diversas ciudades con monumentos e incluso ha marcado el urbanismo de estas, como es el caso del barrio de Velluters en València o el Des canuts en Lyon. En ellos, edificios tan memorables como la Lonja de València, patrimonio mundial de la UNESCO, no pueden estar disociados de la seda, elemento que ha vestido, además, lujosos palacios a lo largo de la historia. Al mismo tiempo, se trata de un patrimonio vivo presente en las actividades culturales de algunas comunidades y en técnicas artesanales que no han perdido su continuidad en el tiempo. Más allá de estos elementos históricos, la seda es un elemento de creatividad puesto que su hilo está presente en los diseños más contemporáneos de la moda actual. La industria textil es, actualmente, valorada por su aportación al desarrollo económico europeo y local. De hecho, según la Confederación Europea de la Industria del Vestido (EURATEX), Europa es el segundo mayor exportador de textiles e indumentaria, empleando hasta 1,7 millones de trabajadores en 171.000 compañías, de las cuales el 99\% son pequeñas y medianas empresas (Euractiv, 2016). Pero, además, la Comisión Europea reconoce la industria de la moda y el textil como uno de los sectores más creativos que no sólo generan riqueza, sino que es estandarte de la cultura, creatividad, artesanía e innovación. A pesar de que la presencia de la seda es relevante en la historia de Europa, no solo a nivel patrimonial, sino también en los aspectos económicos, sociales, científicos, y por ello la seda debería ser el punto de partida para abordar los problemas que plantean los textiles; su valorización está lejos de estar al mismo nivel que otras tipologías patrimoniales. A través del proyecto SILKNOW (Portalés et al., 2018) hemos podido comprobar la falta de estándares y vocabulario controlado en la catalogación de las piezas en el panorama nacional e internacional. Por eso, este proyecto, financiado por la Unión Europea en el marco de Horizonte 2020, pretende conservar este patrimonio a través de un sistema computacional inteligente que permitirá a diversos usuarios conectar en tiempo y espacio elementos sederos gracias a la identificación avanzada de imágenes, un tesauro multilingüe y un telar virtual a través del que documentar y preservar las antiguas técnicas de la tejeduría histórica y la actual, mantenida gracias a los artesanos que mantienen vivo su uso.

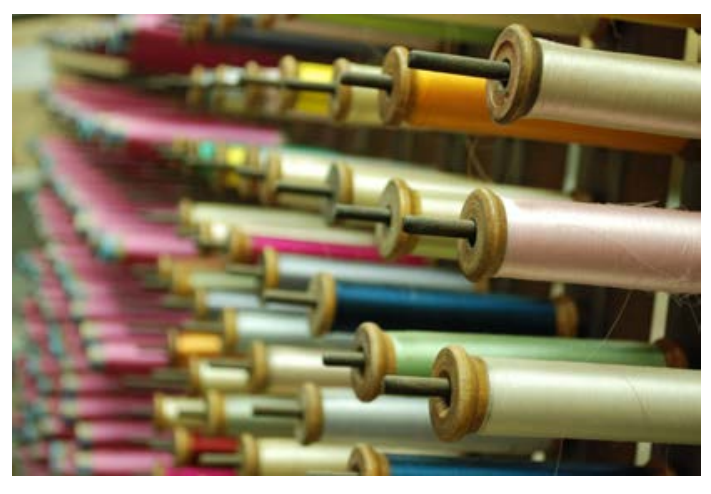

Fuente: Paula Feito Rausell, (2015)

Fig. 1 Fileta, fábrica Garín 1820

\section{El patrimonio sedero: un patrimonio vivo}

El patrimonio cultural abarca tanto los monumentos, sitios, paisajes culturales, colecciones museales (patrimonio material) como los usos, representaciones, las expresiones, los conocimientos, las aptitudes de las comunidades y grupos (patrimonio inmaterial). El patrimonio sedero es uno de los pocos patrimonios culturales que pertenece al llamado patrimonio integral, es decir, es material e inmaterial, puesto que a su alrededor se encuentran los tejidos, los telares o las puestas en carta (material) y dibujos preparatorios y, al mismo tiempo, reúne artesanía, saberes tradicionales e industria (inmaterial). 
En el ámbito español, la historia cultural vinculada a la seda ha tenido una fuerte presencia en distintos territorios y ámbitos. Por un lado, el cultivo de la morera ha configurado la fisonomía de nuestros territorios y ha generado paisajes con una fuerte carga identitaria en lugares como Murcia, Valencia, Toledo o Granada, pero también en otros ámbitos locales. Respecto a la realización de tejidos, la industria de seda tuvo un papel sustancial desde la Edad Media, pero será en el siglo XVIII cuando adquiera un renovado esplendor al calor de las políticas proteccionistas del reformismo borbónico, especialmente en ciudades como Talavera de la Reina, Toledo, Valencia, Granada, Sevilla, Málaga y Murcia, etc., en las que la producción dependía de talleres urbanos, que en el caso de Valencia se organizaban bajo la institución del Colegio del Arte Mayor de la Seda (1686) que reunía al antiguo Gremio de velluters (1479). En estos talleres se elaboraban productos textiles similares, confeccionados con idénticos métodos y técnicas y se regulaban a través de las ordenanzas de sus colegios la uniformidad en los procesos y se garantizaban unos mínimos niveles de calidad, así como fijaba los precios de los productos en el mercado. Pero los grandes centros sederos en el XVIII que concentraban gran parte del flujo comercial fueron, sin duda, Toledo y Valencia, y Lyon, en Francia, desde donde se importaban los tejidos y modelos de seda que conformaron las tendencias de la moda de su época.

No obstante, a pesar de esta relevancia histórica resaltada por numerosos estudios históricos y artísticos (Franch Benavent, 1994; 2000; 2012; Franch Benavent y Navarro Espinach, 2018; Navarro Espinach, 1999), el patrimonio de la seda, que tan presente ha estado en el imaginario visual, cultural y en nuestra historia durante siglos, es hoy un recuerdo cuya memoria se diluye entre la bruma del olvido (Franch Benavent y Alba Pagán, 2017). Desde el punto de vista material, de aquel pasado sedero ha quedado la conformación de un territorio en el que en las viviendas agrícolas se cultivaba el gusano de la seda en desvanes o cámaras (las cambras y andanas de las alquerías y masías del mediterráneo) y la estructura de un paisaje fuertemente asociado a la conformación de las identidades colectivas. Uno de los testigos más relevantes de esta actividad artesanal es la fisonomía urbana del barrio de velluters de València, así como los restos de murallas y puertas por las que se controlaba y fiscalizaba el comercio: las monumentales puertas de Quart y Serranos. El barrio de velluters, dedicado al oficio sedero, ubicado al suroeste de la ciudad, en cuyo punto central, la Plaza del Pilar, actualmente se rememora la tradición sedera a través de la conmemoración del Motín de Velluters con la realización de les fogueres. El 21 de enero de 1856 tuvo lugar el motín como protesta de los trabajadores de la seda por sus condiciones laborales, así como la huelga de hilanderas de 1902. El nombre del barrio se debe a la alta concentración de telares que llegó a tener en 1767 cerca de cinco mil telares. Un oficio, asociado a la industria de la seda, que es visible en la estructura urbana del barrio y en algunos de sus edificios, casas taller o fábricas, como el Palau Tamarit. En estas casas se ubicaban los talleres, conocidos como porxe del velluter, situado en la última planta del edificio formada por vigas de madera. Estos desvanes servían, también, para colocar los cañizos donde se criaba el gusano de seda, las andanas sederas, también llamadas llits de cucs.

Desde un punto de vista inmaterial, el patrimonio de la seda ha estado vinculado a la creación literaria y a los estudios científicos, así como a las manifestaciones artísticas que desde el medievo representan tejidos de seda en sus composiciones y en las indumentarias de los personajes. Desde Cavanilles $(1795,1802)$ a Mayans (1748) o Madoz (1846) la seda ha constituido uno de los intereses más elevados del análisis fisiocrático de los eruditos que analizaban con rigor las ventajas de la producción y su impacto económico en el progreso de las sociedades del setecientos y el ochocientos. Pero, además a conformado el imaginario popular a través de la generación de un vocabulario específico y de dichos y canciones populares asociadas al trabajo artesanal (Bataller y Clavero, 2005). Además, su impacto social, económico y cultural llegó a trascender el ámbito de lo popular y saltar a las páginas de la literatura. El propio Blasco Ibáñez (1904) en su narración sobre el "Alma valenciana”, escribe que el agricultor valenciano "conserva la gallardía del árabe, cuando de un salto monta por el anca la jaca en pelo, para correr la joya. Las modernas costumbres han modificado su traje, afeándolo; pero durante tres siglos ha sido el único agricultor del mundo que vestía de seda. Las faldas de nuestras labradoras, bordadas de rosas. y claveles como las casullas, adornan hoy planos. y sillas en los salones elegantes". Pero también en el Quijote de Cervantes se hace alusión expresa al camino de la seda que durante la edad Moderna unía Murcia con Toledo, desde época de Alfonso X el Sabio, y la seda es imagen recurrente en multitud de autores, como en Góngora y en Quevedo: "Mancebitos de la carda/los que vivís de la hoja,/ como gusanos de seda/tejiendo la cárcel propia...", etc. Pero especialmente, la seda es un patrimonio vivo que está presente también el paisaje festivo tradicional español. La seda forma parte de la indumentaria tradicional española: el traje de la huerta

(cc)) BY-NC-ND 2020, Universitat Politècnica de València 
murciana, del de aragoneses y aragonesas, segovianas, valencianas, castelloneras y alicantinas tienen como base la utilización del tejido de seda, bien en su totalidad, parcialmente, o en algunos de sus elementos. En las Fallas, en la Madalena, en les Fogueres de Sant Joan, mujeres y hombres se visten con tejidos de seda (espolines, indianas, damascos, etc.) o sus imitaciones. Otro tanto sucede con las vestimentas de nuestro patrimonio festivo como el de moros y cristianos. Gracias al mantenimiento de esta tradición, las artesanías vinculadas a la seda se han mantenido, especialmente a través de pequeñas empresas que, en Valencia, siguen tejiendo manualmente el espolín y los damascos en los telares Jacquard, aunque otros saberes como "tirar" hilo de oro o la confección del terciopelo han caído en el olvido debido a la desaparición de la última generación de artesanos. En el caso valenciano, la jubilación de Vicente Enguídanos "el último velluter" ponía fin a la profesión de tejer vellut a mano en España. Un caso particular que debe poner en guardia ante el inminente fin de los últimos tejedores de seda, que no cuentan con el adecuado relevo generacional, cuestión urgente que solo podrá ser solventada a través de una planificación adecuada a nivel nacional con acciones de salvaguarda que gestionen talleres formativos y ocupacionales a través de los que preservar el oficio y los saberes transmitidos tradicionalmente.

En definitiva, el patrimonio de la seda reúne toda una serie de valores inherentes a los bienes culturales inmateriales. En primer lugar, es un patrimonio representativo y singular, especialmente asociado al uso por las comunidades como un patrimonio vivo, en lo que supone de mantenimiento de la especificidad de las expropiaciones culturales y de los conocimientos asociados, vinculado al uso tradicional o a la permanencia evolutiva vinculado al desarrollo local. Colabora en el mantenimiento de expresiones culturales y es testimonio de conocimientos a él asociados, presentando no solo el mantenimiento de usos y conocimientos tradicionales, sino mostrando, además, una evolución en su adaptación al presente como vía de mantenimiento de los conocimientos asociados a las expresiones culturales tradicionales y motor de la innovación y la creatividad. Es, igualmente, un patrimonio inmaterial constituido por procesos culturales dinámicos y procesuales en el que la continuidad histórica está presente, como una manifestación patrimonial que ha tenido una permanencia histórica sin discontinuidades y que se ha transmitido a lo largo del tiempo. Además, se asocia a la presencia de organizaciones colectivas o asociativas que ayudan a preservar los usos y la confección de los tejidos, esto es especialmente relevante en el territorio valenciano, en el que confluyen La Ruta de la Seda y Las Fallas, dos Patrimonios Inmateriales de la Humanidad, como puntales de un patrimonio mucho más complejo y que ha constituido la esencia e identidad de los valencianos e, incluso, ha construido el territorio a través de paisajes culturales reconocibles (Alba Pagán y Martínez Fuentes, 2018, pp. 18-33). No obstante, y a pesar de estos reconocimientos los saberes artesanales vinculados a estos reconocimientos tradicionales no han dado el necesario salto a una estrategia de salvaguarda necesaria y apremiante ante la inminente desaparición de la última generación de artesanos textiles.

\section{Hacia un Plan Nacional}

La seda es un patrimonio vivo que ha tenido continuidad en el tiempo y permanece relevante para una comunidad, por lo que su comprensión holística resulta fundamental para la conservación de dicho patrimonio. Ya en el Documento de Nara (UNESCO, 1994), se especifica la importancia de involucrar a las comunidades para la correcta gestión de un bien patrimonial, además de reconocer que la evolución del patrimonio es un hecho importante pero sin que ello signifique perder su autenticidad. Unos años anterior a este documento es El Convenio sobre la Diversidad Biológica, firmado en la Cumbre de la Tierra de Río de Janeiro de 1992 (ONU, 1992), que si bien se dedica a la promoción del desarrollo sostenible, contiene un apartado sobre la protección de los saberes tradicionales, entendiéndose como "los conocimientos, innovaciones y prácticas de comunidades indígenas y locales que representan los estilos de vida tradicionales pertinentes para la conservación y el uso sostenible de la diversidad biológica". Si bien es cierto que este Convenio está pensado para la protección de los saberes indígenas frente a las grandes industrias, significó un paso más para la protección de los saberes tradicionales, protección que culminaría con la adopción de la Convención para la Salvaguardia del Patrimonio Cultural Inmaterial (UNESCO, 2003), que reconoce el valor de las técnicas artesanales y en particular, en la labor de preservación de los saberes ancestrales, pues "la labor de salvaguardia, en vez de concentrarse en la preservación de los objetos de artesanía, debe orientarse sobre todo a alentar a los artesanos a que sigan fabricando sus productos y transmitiendo sus conocimientos y técnicas a otras personas, en particular dentro de 
sus comunidades". En el texto de la Convención a lo largo de sus 40 artículos específica los distintos instrumentos y códigos éticos susceptibles de adaptarse a diferentes situaciones locales y nacionales para la salvaguarda del patrimonio inmaterial. En ese sentido, el patrimonio sedero cumple todos los requisitos para ser considerado patrimonio inmaterial de relevancia internacional, nacional y local, pero sin embargo en la actualidad no está protegido de una manera correcta, exhaustiva, a nivel nacional, aún cuando en el Artículo 11 del texto de la Convención se especifica que las comunidades deben participar activamente en la identificación y definición de dicho patrimonio. Por ello, resulta imprescindible como una de las primeras tareas en la preservación del patrimonio de la seda, la confección de un inventario para garantizar su salvaguarda (Artículo 12). Para proteger el patrimonio inmaterial sedero no basta con garantizar la elaboración de este inventario, sino que además es necesario hacer políticas activas de conservación. En el caso de España, la Ley 10/2015 en su Artículo IV sección b, establece que el Estado es el que asume la protección del patrimonio cultural inmaterial dejándole a cada comunidad autónoma la prerrogativa de protegerlo también. De esta manera, se garantiza que este tipo de patrimonio esté protegido en todos los niveles gubernamentales y de la administración. Por otra parte, cabe recordar que la dimensión cultural que tiene este tipo de patrimonio hace que en muchos casos tenga asociados bienes materiales muebles e inmuebles que deben ser protegidos, tal y como lo establece la modificación de la LPHE/85 (Ley 10/2015: Artículos 3 y 4). En el caso del patrimonio sedero, éste tiene asociados las propias fábricas y talleres en los que se sigue produciendo esta actividad, maquinaria o utensilios que se utilizan en el proceso de elaboración, los propios tejidos o incluso espacios de memoria como el barrio de Velluters en Valencia. Entre las artesanías que mantienen en el caso valenciano la tejeduría de la seda asociada a las formas tradicionales de confección del espolín y otros tejidos de fibra de seda, confeccionados en telares Jacquard (Fig. 2), destacan Garín 1820 y Catalá, hoy Compañía valencia de la Seda, cuya importancia es similar a la mítica empresa artesanal Luigi Bevilacqua de Venecia (1875), el único telar que, históricamente vinculado al siglo XV, se mantiene en activo entre los más de 200 telares con los que llegó a contar la ciudad del Véneto.

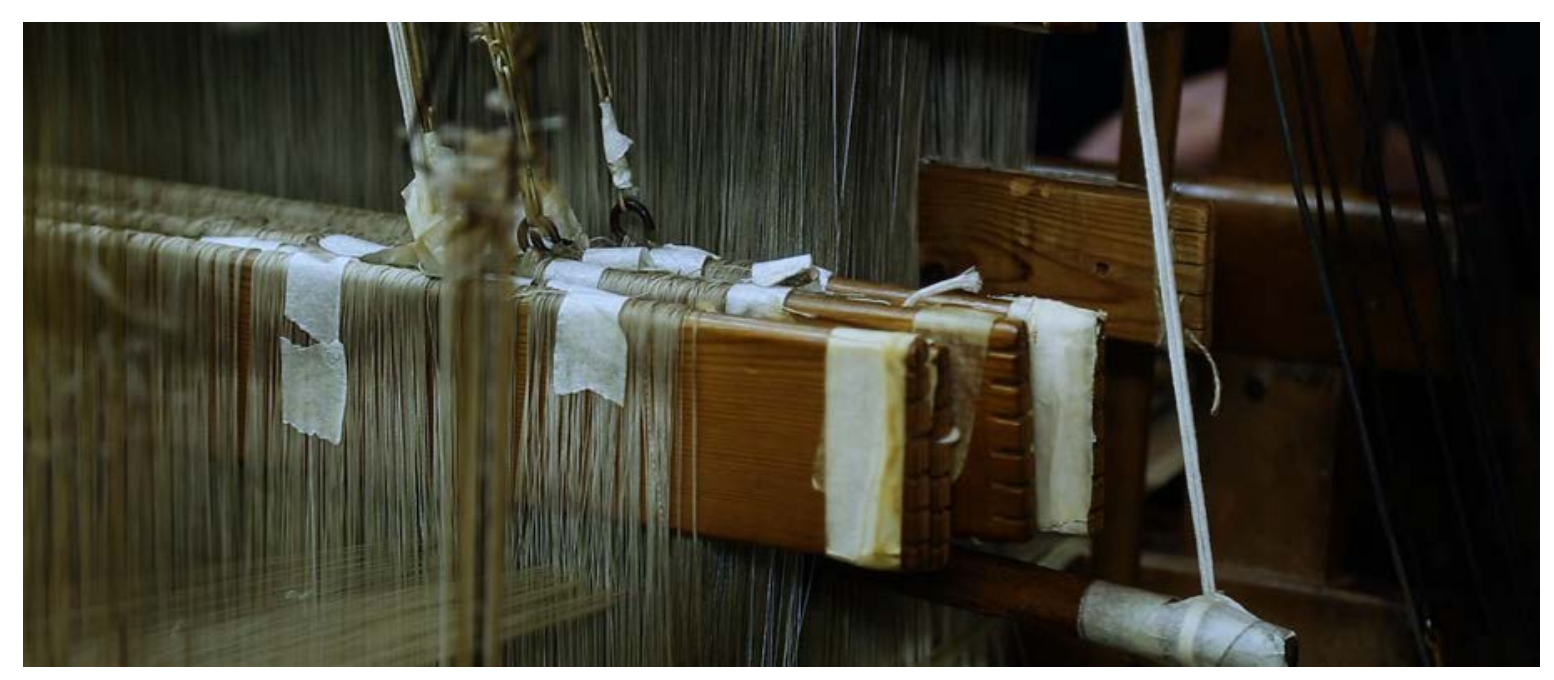

Fuente: José Molins (2014)

Fig. 2 Lizos de un telar Jacquard. Fábrica Garín 1820

SILKNOW (Horizon 2020, $\mathrm{n}^{\mathrm{o}}$ 769504) mediante la investigación del patrimonio sedero europeo ha dado un paso importante en aras de su protección y difusión, a través de talleres de sensibilización y accesibilidad entre las diversas audiencias a las que el proyecto se dirige. En este sentido, SILKNOW se apoya en las propias directrices de la Convención, en específico del Artículo 14, que además de generar sensibilización entre la población local vinculado a este patrimonio, ha dado a conocer tanto los beneficios de la protección de este patrimonio como ha apostado por la generación de identidad asociada a la seda a la vez que apuesta por los medios no formales de transmisión del saber, como parte de la memoria colectiva que es intrínseca al patrimonio inmaterial sedero, generando nuevas narrativas. La difusión y sensibilización del proyecto está alineado con los Artículos 6, 8 y 9 de la Ley 10/2015 que garantizan la divulgación, transmisión, concientización y acceso a este importante patrimonio material e inmaterial, incluyendo los 
conocimientos de los tejedores (Fig. 3). Todo lo anterior, se alinea con la necesidad de tener en cuenta todas los factores que puedan constituir una amenaza y ocasionar un impacto negativo, sea indirecto o directo, a largo o corto plazo, en el patrimonio inmaterial, tal y como lo manifiesta la Ley 10/2015 que remarca la importancia de mantener la autenticidad del patrimonio inmaterial evitándose alteraciones de sus componentes culturales, incluyendo aquellos que atraigan la actividad turística, la cual no debe vulnerar los elementos que lo hacen único. De esta manera, la Ley Nacional se alinea tanto con las directrices de la UNESCO como con el Documento de Nara. En este sentido, es importante tener en cuenta la naturaleza dinámica y viva de este tipo de patrimonio y que, por tanto, no debe ser un obstáculo para su protección, ni mucho menos estar sujeto a juicios externos sobre su valor ya que constituye un patrimonio único, dinámico, recreado y experimentado por diversas comunidades, garantizando su derecho a seguir ejerciendo su actividad, como competencia y conocimientos especializados que han perdurado a lo largo de los siglos. Para la creación de un Plan Nacional Sedero, se podría tener en cuenta el Plan Nacional del Esparto (Ministerio de Cultura de España, 2016) en el que el Estado español a través del Instituto del Patrimonio Cultural de España (IPCE) ha fomentado el estudio científico, técnico y artístico de este patrimonio, siguiendo metodologías propias de la investigación científica, que a su vez han llevado a la adopción de medidas jurídicas, técnicas y administrativas para la reafirmación del Plan Nacional. Esto debería ser un ejemplo de buenas prácticas que podría replicarse en el caso sedero, generando estudios científicos e instituciones que documenten este patrimonio ancestral y que garanticen el acceso desde el respeto a la ciudadanía de su propio patrimonio para su goce, protección y conocimiento.

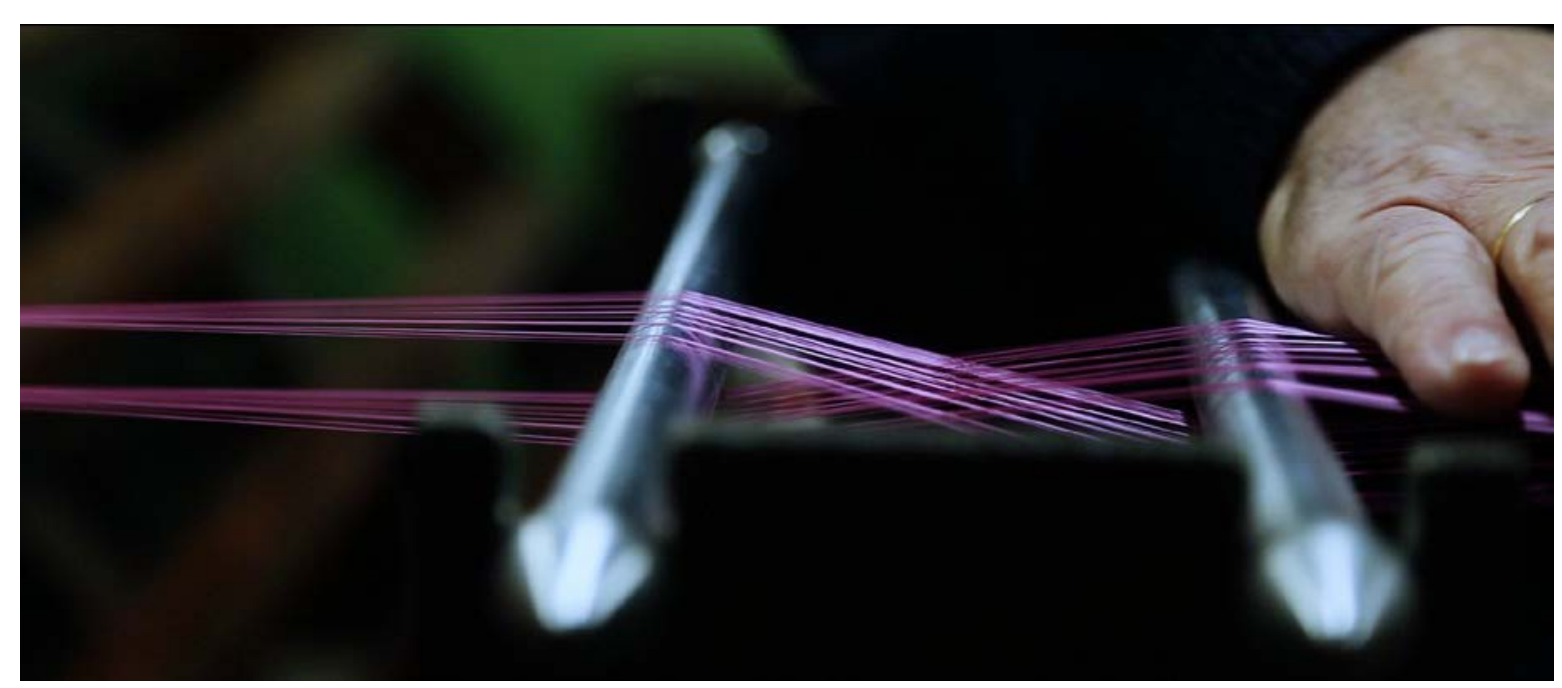

Fuente: José Molins (2014)

Fig. 3 Artesano preparando el urdido. Fábrica Garín 1820

Un Plan Nacional del patrimonio de la seda debería tener en cuenta tanto las Directrices Operativas de la UNESCO, como la Ley Nacional y los planes nacionales que ya se están ejecutando para la aplicación de un correcto marco legislativo que proporcione garantías jurídicas al patrimonio inmaterial. El objetivo principal de un Plan Nacional del patrimonio de la seda es el de establecer las líneas fundamentales que determinen la protección y salvaguardia de este tipo de patrimonio y la búsqueda de su viabilidad en el tiempo. En ese sentido, resulta fundamental que este plan cuente, especialmente, con el trabajo que ya ha realizado SILKNOW, que supone un adelanto a la investigación del importante patrimonio sedero, el cual ha sido respaldado por especialistas en historia, historia del arte, etnología, conservaciónrestauración, pero sobretodo con la importante participación de la artesanía tradicional, ingenieros textiles, tejedores e industria creativa que son parte fundamental de este proyecto. El primer reto al que se enfrenta este tipo de patrimonio es la falta de estandarización del vocabulario referente a la actividad sedera y todo lo que la rodea, el tesauro multilingüe especializado en seda realizado en el seno del proyecto se configura como el primer modelo de tesaurización que va más allá de los vocabularios estándar y especializados y ofrece una estructura que sigue la jerarquización del Getty Institute Research, que además se ofrece como una herramienta de acceso abierto (Léon et al., 2019; SILKNOW, 2020). Por otra parte, la documentación y preservación de las técnicas históricas de tejido resulta 
fundamental, dada la pérdida que se está experimentando en el sector con la falta de relevo generacional. Para ello, SILKNOW está trabajando activamente con la EASD Valencia con el fin de fomentar entre los más jóvenes el interés por continuar esta actividad, entre sectores como el diseño y la moda. En el caso de desarrollarse este Plan Nacional este tipo de iniciativas deberían extenderse a ámbitos más heterogéneos para poner el foco en la pervivencia de técnicas que han perdurado por más de cinco siglos. Al mismo tiempo, gracias a la tecnología, SILKNOW ha desarrollado un "telar virtual" (Gaitán et al., 2019) para reproducir técnicas históricas de tejido, lo que permite a los usuarios descubrir la complejidad, los valores artísticos y artesanales de los textiles de seda antiguos y sus técnicas de tejido, a la vez que preservará para las generaciones futuras el conocimiento artesanal de los saberes tradicionales vinculados a la tejeduría de la seda europea, en claro riesgo de desaparición. El trabajo interdisciplinar de SILKNOW, es un ejemplo de cómo la tecnología resulta fundamental en la preservación y divulgación del patrimonio cultural en el siglo XXI. Finalmente, este proyecto europeo ha desarrollado una herramienta que permite localizar los tejidos de seda en Europa en tiempo y espacio, este mapa garantiza que los usuarios puedan descubrir las conexiones entre países, personas, diseños y épocas. Este instrumento se puede expandir localizando talleres y empresas que siguen ejerciendo la tejeduría tradicional y manual.

\section{Conclusiones}

El patrimonio cultural está formado por elementos materiales e inmateriales que están vinculados a la memoria que generan un complejo relato en el que la comunidad se identifica y forma parte la historia (Fig. 4). Únicamente desde esta mirada se puede ser consciente de la necesidad de preservar el patrimonio cultural para legarlo a generaciones futuras, y para apreciar su poder comunicativo y su enorme potencial para el desarrollo sostenible, el impulso de la creatividad y parte de la economía social, pues es fuente de memoria e inspiración, da sentido al lugar cultural, contribuye a la identidad de las comunidades nacionales y locales generando cohesión social (Communities and Local Government, 2009). Es por todo ello que el patrimonio cultural no debe aislarse del desarrollo, ni de los cambios sociales, puesto que la vinculación emocional, cognitiva, apreciativa y valorativa surgida de la memoria colectiva actúa como agente de preservación del patrimonio asociado a los elementos materiales, inmateriales, culturales y naturales del mismo. Creemos que es completamente necesaria la creación de un Plan Nacional que empiece por establecer una estrategia clara y concisa, sustentada por líneas de difusión y un cronograma que justifiquen la ejecución del plan, su evaluación, para llegar al fin último: la salvaguarda del patrimonio sedero, el cual ha sido y es fundamental para el desarrollo de la historia española y europea. Para ello, es necesario hacerlo desde la perspectiva interdisciplinar que abarque la investigación científica pero también que se nutra de la artesanía, reconociéndola como depositaria y transmisora de la riqueza patrimonial sedera.

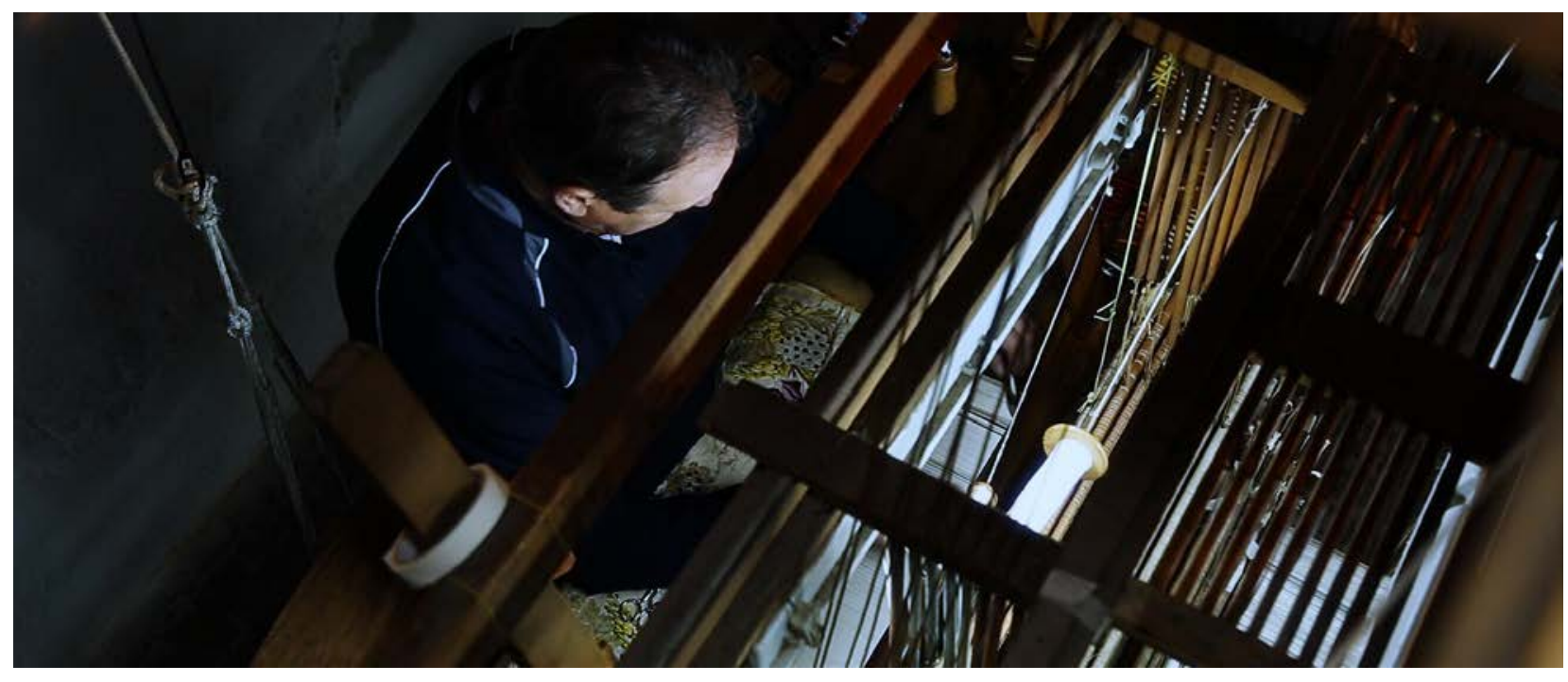

Fuente: José Molins (2014)

Fig. 4 in memoriam Rafael Martínez Soucase, maestro sedero. Fábrica Garín 1820 


\section{Referencias}

Alba Pagán, E., y Martínez Fuentes, C. (2018). La seda valenciana: turismo de patrimonio. Papers de Turisme, 61, 18-33.

Bataller, A., y Clavero, C. N. (2005). Les paraules de la seda: llengua i cultura sericícola valenciana. Valencia: Centre d'Estudis i Investigacions Comarcals Alfons el Vell.

Blasco Ibáñez, V. (1904). (1904). Alma valenciana. Alma española, 2(11), 10-12.

Cavanilles, A. J. (1795). Observaciones sobre la historia natural, geografía, agricultura, población y frutos del Reyno de Valencia (Vol. IV). Imprenta Real.

Cavanilles, A. J. (1802). Descripcion de las plantas que D. Antonio Josef Cavanilles demostró en las lecciones públicas del año 1801: precedida de los principios elementales de la botánica. Imprenta Real.

Communities and Local Government. (2009). Draft Planning Policy Statement 15: Planning for the Historic Environment. Londres. Recuperado de www.communities.gov.uk/documents/planningandbuilding/pdf/consultationhistoricpps.pdf

Euractiv. (2016). European Textiles and Fashion: Facts \& Figures. Recuperado de http://www.euractiv.com/section/innovationindustry/infographic/european-textiles-and-fashion-facts-figures/

Franch Benavent, R. (1994). La producción de seda en el País Valenciano durante el siglo XVIII: distribución geográfica y evolución.

Franch Benavent, R. (2000). La sedería valenciana y el reformismo borbónico. València: Institució Alfons el Magnànim.

Franch Benavent, R. (2012). Del “vellut” al espolín. Estudios sobre la industria valenciana de la seda en la edad moderna. València: Obra propia.

Franch Benavent, R., y Alba Pagán, E. (2017). Los Paisajes de Seda: La memoria rememorada / The Landscapes of Silk: The Remembrance Memory. En Paisajes Turísticos Valencianos: paisajes valiosos, paisajes valorados (pp. 862-880). Valencia: Universitat de València.

Franch Benavent, R., y Navarro Espinach, G. (2018). Las rutas de la seda en la historia de España y Portugal. Valencia: Universitat de València.

Gaitán, M., Alba, E., León, A., Pérez, M., Sevilla, J., y Portalés, C. (2019). Towards the Preservation and Dissemination of Historical Silk Weaving Techniques in the Digital Era. Heritage, 2(3), 1892-1911. https://doi.org/10.3390/heritage2030115

Léon, A., Gaitán, M., Sebastián, J., Pagán, E. A., y Insa, I. (2019). SILKNOW. Designing a thesaurus about historical silk for small and medium-sized textile museums. En Science and Digital Technology for Cultural Heritage-Interdisciplinary Approach to Diagnosis, Vulnerability, Risk Assessment and Graphic Information Models.

Madoz, P. (1846). Diccionario geográfico-estadístico-histórico de España y sus posesiones de ultramar (Tomo XI). Madrid: Imprenta del diccionario Geográfico, a cargo de José Rojas.

Ministerio de Cultura de España. (2016). Plan de Salvaguarda de la Cultura del Esparto. Recuperado 20 de febrero de 2020, de $\mathrm{http} / /$ www.culturaydeporte.gob.es/planes-nacionales/planes-nacionales/salvaguardia-patrimonio-cultural-inmaterial/actuaciones/ plan-de-salvaguarda-de-la-cultura-del-esparto.html

Navarro Espinach, G. (1999). Los orígenes de la sedería valenciana (siglos XV-XVI). Valencia: Ajuntament de València Oficina D’Estadística.

ONU. (1992). Convenio sobre la Diversidad Biológica de Río de Janeiro.

Portalés, C., Sebastián, J., Alba, E., Sevilla, J., Gaitán, M., Ruiz, P., y Fernández, M. (2018). Interactive Tools for the Preservation, Dissemination and Study of Silk Heritage-An Introduction to the SILKNOW Project. Multimodal Technologies and Interaction, 2(2), 28. https://doi.org/10.3390/mti2020028

SILKNOW. (2020). SILKNOW Thesaurus. Recuperado 1 de abril de 2020, de http://skosmos.silknow.org/en/

UNESCO. (1994). Documento de Nara sobre la autenticidad. R. Lemaire \& H. Stovel (Eds.). UNESCO.

UNESCO. (2003). Convención para la salvaguardia del patrimonio cultural inmaterial. 